\title{
A História Dominante do Movimento CTS e o seu Papel no Subcampo Brasileiro de Pesquisa em Ensino de Ciências CTS
}

\section{The Dominant History of STS Movement and its Role in Brazilian Subfield Research in STS Science Teaching}

\author{
Thiago Vasconcelos Ribeiro ${ }^{(\mathbb{B})}$ Brasil \\ Aliny Tinoco Santos ${ }^{(1)}$ Brasil \\ Luiz Gonzaga Roversi Genovese Brasil
}

O presente artigo tem por objetivo problematizar e analisar alguns elementos destacados na literatura nacional a respeito da história dominante de origem do movimento Ciência-Tecnologia-Sociedade (CTS). Entende-se que esta "história dominante", assim caracterizada por ser tratada de forma relativamente padronizada pelos principais trabalhos na área, desempenha um papel importante nas lutas no interior do Subcampo Brasileiro de Pesquisa em Ensino de Ciências CTS. Para a construção do objeto de pesquisa foi empregado o aporte teórico desenvolvido por Pierre Bourdieu da noção de campo. A análise dos dados permite questionar criticamente diversos elementos presentes na forma com que a origem do movimento CTS é apresentada e sinalizar para mecanismos de violência simbólica que assim são tacitamente admitidos e transmitidos no subcampo em questão.

Palavras-chave: Ciência-Tecnologia-Sociedade; campo científico; violência simbólica.

This article intends to discuss and analyze some highlighted elements in the national literature about the dominant history of the origin of the Science-Technology-Society movement (STS). This "dominant history" thus characterized by being treated in a relatively standardized way by the leading works in the field plays an important role in the struggles within the Brazilian Research in Science Teaching STS Subfield. For the construction of the research's object we used a theoretical framework developed by Pierre Bourdieu: the notion of field. The data analysis allows to critically question some elements present in the way that the STS movement origin is presented and signals to the mechanisms of symbolic violence implicitly accepted and transmitted in that subfield.

Keywords: Science-Technology-Society; scientific field; symbolic violence. 


\section{Introdução}

O presente artigo tem por objetivo problematizar e analisar alguns elementos destacados na literatura nacional a respeito da história dominante de origem do movimento CTS. Entende-se que esta história dominante, assim caracterizada por ser tratada de forma relativamente padronizada pelos principais trabalhos na área, desempenha um papel importante nas lutas no interior do Subcampo Brasileiro de Pesquisa em Ensino de Ciências CTS (Ribeiro, 2015) o qual pretende-se discutir a seguir.

O Subcampo Brasileiro de Pesquisa em Ensino de Ciências CTS consiste em um microcosmo social integrante de um campo de pesquisa mais amplo denominado de Campo Brasileiro de Pesquisa em Ensino de Ciências. Logo, objetivar o ponto de vista dominante sobre a história de origem do movimento CTS, exige mobilizar instrumentos teóricos e práticos que permitam a construção sistemática do objeto a ser analisado - a história contada sobre e para o subcampo em questão. Trata-se, portanto, de um exercício de vigilância epistemológica que visa realizar algumas rupturas e avanços.

Uma primeira ruptura ocorre com essa espécie de "historicismo espontâneo" recorrente em grande parte das reconstruções históricas, o senso comum que constrói a história de forma linear, única e a problemática e que permanece não questionado. O que se chama aqui de senso comum da história é justamente a completa ausência de metodologia e rigor para se operar uma verdadeira reconstrução histórica de forma crítica e heuristicamente relevante, capaz de superar o conhecimento imediato e superficial da história que existe e persiste na produção científica. Pretende-se, portanto, romper com as opiniões primeiras acerca dos "fatos" históricos que se apresentam como uma coletânea falsamente sistematizada, sob uma forma linear e determinista, que é utilizada para emitir julgamentos e impor valores e significações. Tal imposição, cuja aceitação ocorre de forma inconsciente e velada no subcampo, somente exerce sua força simbólica mediante um trabalho permanente de ocultamento do arbitrário presente na origem de suas próprias escolhas e definições (Bourdieu, \& Chartier, 2012). Dessa forma, o presente trabalho também busca romper com as aparências de unanimidade que emergem das reconstruções históricas dominantes nesse universo particular responsável pela produção nacional das pesquisas em ensino de ciências CTS, típica da ação contínua de formas de violência simbólica que atuam sistematicamente nas estruturas em questão.

Logo, busca-se realizar aqui uma leitura crítica do histórico sobre CTS apresentado nas principais produções do subcampo brasileiro, por meio de uma análise da forma como a origem histórica do movimento CTS é abordada por essas produções. Consiste em uma operação de objetivação fundamentada pelo aporte teórico de campo proposto por P. Bourdieu. Ao se fundamentar a leitura dessas produções por meio da teoria do campo, buscou-se desvelar a forma com que essa história dominante é mobilizada na dinâmica das lutas científicas, isto é, ativada e reativada como estratégia consciente e inconsciente de convencimento, atuando na forma como a verdade é estabelecida e tacitamente imposta aos demais agentes, segundo hierarquias mais ou menos explícitas 
nas estruturas do Subcampo Brasileiro de Pesquisa em Ensino de Ciências CTS (Ribeiro, 2015). Consequentemente, as reconstruções históricas aqui analisadas têm o objetivo, também, de conscientizar os pretendentes/aspirantes ao subcampo, agentes dominados na e pela estrutura e que estão adentrando nas lutas travadas em seu interior, da violência simbólica a que estão submetidos e que é tacitamente exercida sobre todos os agentes pertencentes ao campo em maior ou menor intensidade. Além de desvelar e conscientizar, procura-se aqui instrumentalizar leitores e agentes do subcampo, sobretudo os agentes dominados que, devido à sua própria posição desprivilegiada na estrutura, não percebem tais elementos que reforçam a própria relação de dominação em que se encontram.

Por fim, este texto tem, ainda, o objetivo de evidenciar esse instrumento de diferenciação que é a história dominante de um determinado campo, que atua como um mecanismo diferenciador dos agentes em constante luta pela (re)definição dominante da história do movimento CTS.

\section{O papel da história em um mercado de produção simbólica}

Os campos de produção dos bens culturais são, segundo Pierre Bourdieu, universos sociais baseados na crença em seus próprios valores e produtos. Tais campos existem e persistem em um determinado tempo e espaço porque conseguem produzir, simultânea e eficazmente, produtos simbólicos e a respectiva necessidade por tais produtos. Mediante a instauração de um mercado de (re)produção e consumo de bens simbólicos específicos, é estruturado um espaço de lutas entre agentes que se ocupam da produção, reprodução e transformação desses bens. O que está em disputa entre esses agentes é a própria definição dos objetos por eles produzidos, ou seja, eles estão em constante luta pela (re)definição da verdade sobre os bens simbólicos produzidos no campo (Bourdieu, 2008).

Desse modo, a história dominante registrada e reafirmada no interior de um campo está intimamente associada à produção e reprodução de sua crença coletiva que, historicamente, através das lutas anteriores, se impôs (e se impõe a todo instante) de forma dominante como "A história do campo". A idealização de um marco histórico importante, como o que institui um campo, bem como os atos sucessivos de sua permanência temporal e espacial, a sua sobrevivência no espaço social em relação aos demais campos de produção simbólica já consolidados, que é apresentada sob uma representação relativamente linear de "fatos" e "acontecimentos", tem como prerrogativa primeira (re) afirmar a existência "real” do campo. Sinaliza que o campo existe de forma objetiva e é assim percebido por uma quantidade significativa de agentes. Uma vez estabelecido isso, o objetivo seguinte é mostrar que o "jogo merece ser jogado", ou seja, faz-se referência histórica à sua relevância e à de seus produtos - evidencia-se a necessidade por tais produtos. A história, portanto, é um dos instrumentos de diferenciação do subcampo no espaço social em relação aos demais campos de produção simbólica. Uma vez convencidos de que o campo evidentemente existe, que é realmente importante que ele 
exista, e que o “jogo vale a pena o investimento”, o cenário construído consequentemente define e demarca quais são as posições dominantes no campo e quais agentes as ocupam num determinado momento. Por fim, há o objetivo de reprodução da ordem social, uma vez que a história é uma forma de fazer com que as "leis fundamentais" do campo sejam permanente e incessantemente lembradas e reafirmadas também para e pelos novos pretendentes/aspirantes ao campo.

Evidentemente, a crença coletiva é construída coletivamente. Cada agente atua no campo visando demarcar os fundamentos da crença coletiva segundo seus próprios interesses específicos, de modo que todos, de forma desigual, "tendem sempre a desviar em seu benefício a autoridade de que dispõem, portanto, a impor como única legítima sua variante própria da visão dominante de mundo" (Bourdieu, 2008, p. 70). Destaca-se apenas que a dominação, mais do que a manifestação mecânica, direta e simples de um efeito exercido pelos dominantes sobre os dominados é exercida indiretamente enquanto efeito de uma trama complexa de ações, posições e tomadas de posição que também impõem limitações a cada um dos agentes dominantes na estrutura, se tornando, assim, dominado pela estrutura que emprega para exercer a dominação e que influencia as suas escolhas e os seus investimentos.

A análise das reconstruções históricas das origens do movimento CTS aqui apresentada também assume uma posição nas lutas travadas no interior do Subcampo Brasileiro de Pesquisa em Ensino de Ciências CTS. Com efeito, é apresentado aqui um ponto de vista particular sobre essas reconstruções históricas e sobre a própria estrutura do subcampo CTS. Portanto, esta análise das reconstruções históricas também contribui para a (re)construção de uma realidade de acordo com interesses e necessidades específicas daqueles que aqui as reescreve, as reconstrói e as reinterpreta. Logo, a análise histórica apresentada tem como objetivo a diferenciação dos seus autores em relação aos demais agentes do subcampo, enquanto agentes inseridos e interessados neste espaço de conflitos. Trata-se de uma reconstrução histórica com duplo interesse, utilizada como instrumento de questionamento das concepções basilares do subcampo analisado com o objetivo de fazer avançar o entendimento produzido sobre si próprio e como um instrumento de luta pela transformação das relações de força estabelecidas em seu interior.

As lutas travadas no interior de um determinado campo são guiadas por uma forma particular de illusio cultivada no e pelo campo. A illusio consiste em uma forma específica de interesse tacitamente produzida, reproduzida e inculcada em todos os agentes que pertencem ao universo em questão e que motivam todos os atos de investimento simbólico realizados no campo. Nesse contexto, a referência recorrente à história do campo consiste em um mecanismo eficaz de produção, reprodução e reafirmação da própria illusio. Mais ainda, evidencia a doxa, aquilo que está na base da crença do campo e que permanece fora da disputa e da discussão por ser algo aceito por todos aqueles que decidem entrar no jogo. Esse consenso fundamental sobre os próprios fundamentos do campo, amplamente sublimados na estrutura, somente se torna real 
mediante a submissão dóxica de seus agentes que tacitamente proíbe o questionamento às suas crenças mais fundamentais. Esse campo da doxa, presente em qualquer campo de produção de bens simbólicos, produz:

uma censura ao mesmo tempo mais radical e invisível porque é constitutiva do próprio funcionamento do campo, que se refere ao conjunto do que é admitido pelo simples fato de pertencer ao campo, o conjunto do que é colocado fora de discussão pelo fato de aceitar o que está em jogo na discussão, isto é, o consenso sobre os objetos da dissensão, os interesses comuns que estão na base dos conflitos de interesse, todo o não discutido, o não pensado, tacitamente mantidos fora dos limites da luta. (Bourdieu, 1983, p. 146)

A partir do que é conhecido e reconhecido como crença fundamental legítima do campo se desenrolam incessantemente as disputas em torno da verdade do campo. Logo, a história do campo também é um objeto permanente de disputa, porque se trata de um mecanismo de consagração dos agentes dominantes e dos problemas e metodologias conhecidas e reconhecidas como legítimas pelos demais agentes do campo.

A imposição dos problemas e metodologias que resistem e persistem no campo dos problemas e das metodologias em permanente disputa são tidas como as produções dominantes no campo. Tais produções se impõem sobre os demais agentes que atuam no campo, em maior ou menor intensidade dependendo da posição ocupada por cada agente, mediante violência simbólica, exercendo seus efeitos de dominação sobre todo o campo. A dominação somente adquire a sua autoridade e se torna legítima a partir do momento em que dissimula os mecanismos arbitrários engendrados em suas escolhas e em suas tomadas de posição, isto é, passa a exercer no campo uma violência simbólica. Desse modo, a violência simbólica se exerce ocultando seus próprios mecanismos de opressão e imposição, por ser uma espécie de:

violência suave, insensível, invisível a suas próprias vítimas, que se exerce essencialmente pelas vias puramente simbólicas da comunicação e do conhecimento, ou mais precisamente, do desconhecimento, do reconhecimento ou, em última instância, do sentimento. Essa relação social extraordinariamente ordinária oferece também uma ocasião única de apreender a lógica da dominação, exercida em nome de um princípio simbólico conhecido e reconhecido tanto pelo dominante quanto pelo dominado. (Bourdieu, 2014, p. 7-8)

Assim, os princípios simbólicos explícitos e implícitos na história dominante são aqui identificados, caracterizados e discutidos, bem como os seus efeitos produzidos na e pela estrutura estudada. Os recursos metodológicos de escolha, sistematização e análise de dados mobilizados no esforço de objetivação da história dominante no Subcampo de Pesquisa em Ensino de Ciências CTS são, a seguir, apresentados.

\section{Metodologia}

Escapar à ilusão da transparência dos fatos sociais (Bourdieu, 2010a), isto é, superar o conhecimento imediato que o historicismo espontâneo pressupõe e impõe, exige um questionamento epistemológico permanente que permita chegar à compreensão 
conquistada a partir de uma problemática construída e reconstruída, sob uma incessante vigilância epistemológica. Superar o historicismo espontâneo exige, ainda, uma desconstrução sistemática dos pressupostos que permanecem não questionados no subcampo em questão, e a sua posterior reconstrução à luz de um referencial teórico pertinente que permita desvelar o oculto e evidenciar interesses tácitos associados a escolhas arbitrárias que se impõem como únicas e evidentes e, portanto, exercem o seu poder simbólico num determinado campo.

Parte da construção desse objeto que é o Subcampo de Pesquisa em Ensino de Ciências CTS, consiste na objetivação da história dominante visando desvelar os mecanismos simbólicos engendrados tacitamente na história contada no campo e para o campo. Consciente dos efeitos científicos e políticos associados à construção realizada, que pretende evidenciar instrumentos de dominação simbólica e se tornar ela própria um instrumento elaborado de luta no interior do subcampo, pretende-se colocar em questão aqui o ato de fé simbólico presente nessa estrutura, executando um questionamento de suas crenças fundamentais que, por serem percebidas como tal pelos demais agentes, permanecem inquestionáveis. Esse trabalho de desestabilização de certezas, mais do que romper com um questionamento simples e ingênuo, tem o papel de problematizar os princípios de visão e de divisão, que estruturam a percepção dos agentes e que orientam os recortes realizados - e, assim, (re)constroem a realidade. Dessa forma, explicitar que aquilo que é "evidente" nada mais é senão uma construção de "evidências" interessadamente construídas em meio às relações de força existentes e que atuam de forma permanente nesse processo de construção, consiste em uma importante estratégia de desestabilização dessas certezas que permanecem inquestionáveis.

Pensar relacionalmente a história do subcampo CTS significa pensar a função desempenhada por ela em meio à estrutura das relações de força e das lutas pela conservação ou transformação dessa relação de forças, e a forma com que ela se altera dependendo do estado das lutas dentro e fora da estrutura considerada. Operar esse tratamento à história tem relativa importância na construção do objeto, pois permite questionar os princípios de visão e divisão (classificação) e os sistemas de categorias nas quais está afirmada e, consequentemente, permite operar o questionamento sistemático e necessário para o sistema de categorias aqui construído. Assim, a discussão metodológica desempenha um papel importante, pois (i) permite a explicitação e formalização dos critérios implícitos de objetivação da história dominante, (ii) possibilita o controle lógico dos pressupostos teóricos e práticos que guiam a construção do objeto, (iii) auxilia a determinação do universo de propriedades relevantes e pertinentes para a sua caracterização e (iv) garante coerência ao processo inventivo/criativo, também teórico e prático, sobre a realidade construída e objetivada (Bourdieu, 2011). Logo, as decisões tomadas de forma consciente são devidamente explicitadas, não sendo caracterizadas como um conjunto de escolhas que se fazem desaparecer (intencionalmente) enquanto escolhas e se escondem do questionamento crítico ao se mostrarem como óbvias e evidentes. 
Visando esclarecer e discutir a seguinte problemática: "Quais elementos e princípios simbólicos de dominação podem ser evidenciados nas construções históricas apresentadas na literatura dominante do Subcampo Brasileiro de Pesquisa em Ensino de Ciências CTS?", foi realizada uma análise de conteúdo (Bardin, 2011) de caráter qualitativo (Bogdan \& Biklen, 1994). A escolha por esse determinado método de construção e análise de dados foi feita devido à sua pertinência em trabalhar e sistematizar a análise da história afirmada e defendida pelos agentes dominantes do subcampo e a sua posterior inferência. O primeiro desafio para a pesquisa foi identificar os principais trabalhos nacionais em CTS. Dessa forma, foi realizada uma busca por trabalhos que traziam resultados de levantamentos bibliográficos, em revistas e eventos científicos nacionais da área de ensino de ciências. Logo, durante a fase da pré-análise foi realizada uma leitura flutuante (Bardin, 2011, p. 126) dos trabalhos obtidos nessa busca inicial: Abreu, Fernandes \& Martins, 2009; Araújo, 2009; Chrispino, Lima, Albuquerque, Freitas \& Silva, 2013; Correa \& Araùjo, 2011; Lopes et al., 2009; Mezalira, 2008; Sutil, Bortoletto, Carvalho \& Carvalho, 2008. Durante a leitura flutuante, foram apreendidos alguns elementos históricos recorrentes em pesquisas CTS brasileiras e identificados os trabalhos mais citados por essas pesquisas. Levando em consideração todas as dimensões suscitadas pela construção do objeto, intrinsecamente orientados pela teoria do campo (Bourdieu, 1983; 2010a; 2010b; 2011) e, portanto, lançando um olhar objetivante e interessado sobre o panorama apreendido pelas impressões levantadas durante a leitura flutuante, foi estabelecido e demarcado - em um momento posterior a essa contextualização inicial operada na leitura flutuante - o conjunto de documentos que foram submetidos aos procedimentos analíticos - o corpus da pesquisa.

O corpus adotado foi construído a partir dos dados apresentados em um extenso levantamento bibliográfico publicado recentemente (Chrispino et al. 2013). Nele, ao analisarem as citações presentes em 88 artigos CTS publicados em 20 periódicos nacionais de pesquisa em ensino de ciências, no período compreendido entre 1996 a 2010, os autores identificaram os trabalhos mais citados. Os artigos analisados forneceram um total de 394 fontes bibliográficas que foram analisadas utilizando-se o software livre PAJEK, que organizou os dados em redes de citações. A partir da rede de citações construída, os autores identificaram os 13 trabalhos mais citados pelos artigos analisados. Conforme afirmam os próprios autores:

Os 13 trabalhos mais citados resultantes da pesquisa podem ser encarados como leitura obrigatória para entendimento do que seja e o que produz a área. É o ponto comum, é o consenso, se não construído intencionalmente, certamente estabelecido pela tradição. (Chrispino et al. 2013, p. 467, grifos nossos)

Ao utilizarem a expressão "leitura obrigatória", os autores dão um indicativo do conhecimento e reconhecimento do peso simbólico relativo conquistado por tais trabalhos e seus autores, que conseguiram "deformar o espaço" (Bourdieu, 2004a) à sua volta e demarcar algumas posições dominantes no subcampo CTS brasileiro.

Os dados apresentados em Chrispino et al. (2013) são bastante úteis à investigação 
aqui apresentada, pois mostram os resultados de um amplo levantamento em vários periódicos de pesquisa em Ensino de Ciências, evidenciando os textos CTS mais citados pelas pesquisas brasileiras. Logo, a escolha do corpus levou em consideração principalmente a amplitude do estudo realizado, o qual acredita-se apresentar resultados significativos o suficiente para serem utilizados nesta pesquisa.

É importante destacar, porém, que as inferências e conclusões realizadas por Chrispino et al. (2013) são relativamente limitadas, principalmente por tratarem o universo dos textos pura e simplesmente, desconexas de seus contextos e das relações ali estabelecidas, não considerando o aspecto relacional existente entre as produções teóricas e as estruturas objetivas e incorporadas que tornam tais produções possíveis. Uma análise relacional nesse contexto poderia, talvez, sinalizar para uma relação estrutural entre as citações, entre os agentes que se citam e os que fazem questão de não se citarem. Ainda assim, o levantamento sinaliza que os autores pesquisados, ao fazerem parte do subcampo CTS e se posicionarem em meio às lutas pela autoridade científica ali travadas, reconhecem os trabalhos mais citados como uma espécie de requisito de entrada ao campo e de acesso aos objetos que estão em disputa. Entretanto, o termo “certamente estabelecido pela tradição" pode ser visto como uma sinalização traiçoeira, pois, apesar de apontar para a existência de imposições e determinações feitas por meio do subcampo e sobre o subcampo, omite todo um esforço de conquista de autoridade que acompanhou, e acompanha, as lutas pela autoridade simbólica das quais as obras e seus autores conquistam e extraem a sua legitimidade para criar as "verdades" do campo e as imporem enquanto discurso dominante. Essa é uma das rupturas possíveis de se operar ao pensar relacionalmente o objeto de pesquisa.

Dos 13 trabalhos mais citados na área, 9 são produções nacionais e constituem aqui o corpus a ser analisado: 1) Santos e Mortimer (2002); 2) Auler e Bazzo (2001); 3) Auler (2002); 4) Bazzo (1998); 5) Bazzo, Von Linsingen e Pereira (2003); 6) Auler e Delizoicov (2006); 7) Amorim (1997); 8) Cruz e Zylbersztajn (2001);9) Auler e Delizoicov $(2001)^{1}$. Esses trabalhos apresentam a percepção dominante do subcampo brasileiro sobre diversos aspectos das pesquisas em educação CTS - entre eles a percepção sobre a história dominante de origem do movimento CTS. Todos os textos foram lidos na íntegra e as referências históricas demarcadas, preparando o material para o posterior trabalho de codificação.

O trabalho de codificação dos dados consistiu na construção de categorias de análise a partir das operações de recorte efetuadas ao corpus constituído. Foram delimitadas unidades de registro (referências históricas de origem e estabelecimento do movimento CTS); e unidades de contexto (estruturação dos pressupostos teóricos do Subcampo Brasileiro de Pesquisa em Ensino de Ciências CTS com/contra o qual e a história foi analisada relacionalmente). O aporte teórico adotado forneceu um sistema de categorias prévias que direcionaram a análise, que foi confrontado com os dados

1 A sequência de apresentação dos textos integrantes do corpus de análise levou em consideração a quantidade de citações identificadas pelo levantamento realizado por Chrispino et al. (2013), o que significa que os trabalhos são apresentados aqui dos mais citados 1) para os menos citados 9). 
construídos, fornecendo parâmetros de categorização pertinentes para produzir as inferências e interpretações correspondentes consideradas relevantes.

Tais parâmetros de categorização buscaram identificar alguns instrumentos simbólicos que exercem poder no e sobre o subcampo por meio das construções históricas dominantes sobre o movimento CTS. Nessa direção, as categorias de análise construídas dentro desses parâmetros são: o efeito da sigla CTS; a afirmação da existência objetiva e simbólica do movimento CTS; o contrato social; a illusio e a doxa; os problemas e metodologias dominantes; os elementos de diferenciação na estrutura; e os falsos problemas. As análises das categorias buscaram evidenciar a forma com que a violência simbólica se manifesta ao longo das (re)construções históricas dominantes no Subcampo Brasileiro de Pesquisa em Ensino de Ciências CTS e, ainda, sinalizar algumas das suas implicações nas lutas travadas em seu interior e na produção de sua crença coletiva.

Como em todo espaço de produção simbólica, o que inclui os espaços de produção científica como o Subcampo Brasileiro de Pesquisa em Ensino de Ciências CTS, os produtos simbólicos - os textos - analisados procuram estabelecer uma verdade particular e específica como a verdade legítima sobre a pesquisa em ensino de ciências CTS. Por se tratarem de trabalhos dentre os mais citados pelas próprias pesquisas em ensino de ciências CTS, podem ser considerados trabalhos dominantes na área e como tal, exercem efeitos de dominação sobre os demais pesquisadores ${ }^{2}$. Tendo em vista todos os elementos aqui apresentados pertinentes às relações estabelecidas nos campos de produção simbólica, em particular o subcampo CTS, as sessões seguintes discutem a forma com que essa história dominante é apresentada nos trabalhos aqui analisados.

\section{Origens históricas do movimento CTS - os efeitos do ponto de vista dominante}

Pensar o movimento educacional CTS como um subcampo implica opor-se ao ideal de "comunidade científica" pacífica, enquanto lar do consenso, uma construção fictícia que exerce efeitos reais nas estruturas e nas representações formadas sobre essas estruturas (Bourdieu, 2004b). Um desses efeitos consiste no ocultamento das lutas em curso no interior do campo científico, pela definição da verdade e dos valores de seus produtos. A desconstrução e ruptura com tais noções fictícias podem dar contribuições importantes ao próprio subcampo em questão, uma vez que permitem problematizar elementos que permanecem não discutidos ou são percebidos (ou, ainda, são levados a serem percebidos) como não problemáticos. Nesse sentido, problematizar aquilo que é percebido como aproblemático e que, por isso, escapa a toda e qualquer discussão de suas prerrogativas e efeitos, ou seja, objetivar o ordinário, o invisível, que permanece inquestionável por se fazer ver e ser visto como banal, pode possibilitar avanços e compreensões acerca dos mecanismos utilizados para se estabelecer as "verdades" no

\footnotetext{
2 Evidentemente, apenas o número de citações não é suficiente para caracterizar determinado pesquisador ou grupo de pesquisadores como um agente dominante do campo. Essa caracterização exige evocar outros elementos e a mobilização ampla de dados mais detalhados. A caracterização dos agentes dominantes e dominados e do próprio Subcampo Brasileiro de Pesquisa em Ensino de Ciências CTS é melhor discutida em Ribeiro (2015).
} 
subcampo e saber se essas verdades são, de fato, verdadeiras ou se consistem em falsas verdades construídas e legitimadas ao longo das disputas anteriores.

Tendo em mente tais aspectos, pensar relacionalmente a história dominante é reconstruí-la e problematizá-la de forma intrínseca às lutas que estão em curso no subcampo. Tornar a história problemática é, portanto, problematizar o próprio subcampo em si, colocando em dúvida algumas de suas bases mais fundamentais, tornando-as alvo de um questionamento epistemológico, uma forma de provação (provocação) permanente, em vias de refiná-las e torná-las cientificamente mais progressistas. Dito isso, passa-se agora para as discussões de cada uma das categorias.

\section{O efeito da sigla CTS}

Com efeito, a história desempenha, consciente ou inconscientemente, a função de "oferecer raízes, referências e identidades àqueles que, talvez, careçam desses elementos" (Bourdieu \& Chartier, 2012, p. 53). E dentre os elementos constituintes de referência para o subcampo CTS, a análise aqui apresentada inicia-se com um elemento de fundamental importância na história, aquilo que se tem de mais visível em todos os trabalhos produzidos no campo, que possui presença recorrente nas reconstruções históricas de origem do movimento CTS fornecidas pelo subcampo, mas que, curiosamente, permanece fora do tratamento histórico ou das análises e discussões históricas de sua origem: a sigla CTS. Nenhum dos trabalhos analisados aqui faz alguma sinalização sobre a origem histórica do termo ciência-tecnologia-sociedade ou de sua sigla. Ambos são tidos como dados e, dessa forma, naturalizados em todos os trabalhos que integram o corpus de análise. A presente categoria, portanto, questiona a falta de questionamento da literatura dominante sobre as origens, os significados e efeitos produzidos com a imposição de um nome e de uma sigla para a caracterização de movimentos diversificados em vias de construção em diversos locais do espaço social.

Segundo Aikenhead (2005), a expressão ciência-tecnologia-sociedade, e a sua sigla "CTS", surgiram no final da década de 1970 e início da década de 1980. Nesse período, ele destaca o trabalho de Paul Hurd titulado "Science, technology, and society: new goals for interdisciplinar science teaching", publicado em 1975; o "Project Synthesis" proposto por Harms e Yager em 1977; e o trabalho "Teaching and learning about science and society” escrito por John Ziman (1985) publicado originalmente em 1980. Tais trabalhos começam a lançar mão dos termos "science-technology-society" e "STS” para designar um tipo de educação científica específica. Particularmente, um trecho do trabalho de Ziman chama a atenção por destacar uma característica marcante do movimento CTS que é a diversidade de abordagens e denominações que recebiam os diversos estudos sobre a ciência e a tecnologia:

Es éste un tema que recibe diferentes nombres, en estilo llano o pomposo. Estudios sociales sobre la ciencia; ciencia de la ciencia; ciencia y sociedad; responsabilidad social de la ciencia; teoría de la ciencia; estudios de la política de la ciencia; relaciones sociales de la ciencia y la tecnología; historia, filosofía, sociología de la ciencia, de la 
tecnología, del conocimiento; etc. Llamémosle, crípticamente, CTS, abreviatura de ciencia, tecnología y sociedad. (Ziman, 1985, p. 9)

A emergência de diversos trabalhos destacando a sigla CTS e a expressão "ciência-tecnologia-sociedade", ao contrário de estabelecer um nome próprio a algo que já existia, significava um grande esforço coletivo de construção e de convencimento de agentes que já se encontravam relativamente próximos no espaço social e inclinados a se interessarem por problemas semelhantes. Esse esforço coletivo pode ser sinalizado pela própria citação acima, que reúne uma quantidade significativa de nominações diferentes para trabalhos e abordagens relativamente próximos e, provavelmente, em disputa por se consolidar como a nominação oficial do campo.

O efeito da sigla CTS surgiu, então, como parte desse trabalho coletivo de construção. O trabalho - e, consequentemente, a energia mobilizada - necessário para a construção desse artefato social, o campo de pesquisa em CTS, é simultaneamente prático e teórico, num esforço para aglutinar tanto recursos humanos/institucionais quanto conceituais/simbólicos capazes de tornar tal construção viável. Ela se torna possível mediante o estabelecimento de uma identidade cultural, própria e específica, o qual a instituição de uma sigla tal como CTS ajudou a criar. O processo de construção dessa identidade própria realizou um trabalho simbólico que permitiu aos agentes se reconhecerem mutuamente e a criarem mecanismos próprios para oficializarem esse reconhecimento.

A construção dessa identidade é colocada fora das discussões históricas do Subcampo Brasileiro de Pesquisa em Ensino de Ciências CTS, atuando como um mecanismo de ocultamento do trabalho simbólico despendido para a construção desse grupo social unificado. $\mathrm{O}$ ocultamento da origem da denominação oficial na literatura dominante do subcampo CTS brasileiro indica uma intenção, possivelmente inconsciente, de transmitir a ideia de que a constituição do movimento CTS em si foi algo que ocorreu "naturalmente", quando, na verdade, houve todo um trabalho de mobilização coletiva e, provavelmente, de disputa em torno do nome e da sigla. Um indicativo de que há disputas em curso sobre o nome do campo e a sua respectiva sigla, pode ser sinalizado pelos trabalhos da área que empregam a sigla CTSA, acrescentandose a palavra "Ambiente" à nomenclatura original. Isto tem sido justificado indicando uma apropriação de aspectos referentes à problemática ecológica ambiental às discussões CTS (Pedretti, Bencze, Hewitt, Romkey \& Jivraj, 2006). Esse ocultamento das disputas sobre a sigla inscreve-se num processo de universalização e consolidação de uma identidade de grupo dominante - devido à posição privilegiada dessa visão de mundo e de grupo no próprio subcampo em análise - comum à formação de campos de produção simbólica e que somente pode se propagar na medida em que se torna uma expressão da violência simbólica exercida pelo e sobre o subcampo. Ao se tornar um ato de violência simbólica no interior da dinâmica de produção do Subcampo Brasileiro de Pesquisa em Ensino de Ciências CTS, a sigla CTS passa a ser vista como algo natural, tanto fora quanto dentro do subcampo, o que fortalece a tendência de não questionamento e de aceitação da 
mesma. A atenção volta-se, então, para outros problemas que são colocados em jogo.

O trabalho simbólico de unificação e de universalização, no qual não atua somente o efeito da sigla CTS, mas todas as demais categorias expostas ulteriormente, visa não somente constituir o conhecimento e o reconhecimento entre os agentes, sua mobilização em torno de determinados objetos, inclinando-os ao investimento e, assim, estabelecer a construção de uma identidade coletiva e de um grupo unificado; mas, também, dissimula a construção de falsos consensos sobre a estrutura. O "movimento CTS", a exemplo dos diversos movimentos destacados na história corrente, tal como o "movimento sindical", é retratado como uma entidade, um sujeito coletivo uniformizado, intencional e consciente. Uma noção mistificada e mistificadora das representações dos agentes que com ela se identificam, ao produzir uma imagem social do subcampo CTS sobre si mesmo, para si mesmo e para os demais agentes externos. Trata-se de uma imagem composta por uma construção teórica e prática que exerce efeitos científicos e políticos, uma vez que omite todo um processo de lutas anteriores e, consequentemente, as atuais, pela definição da verdade do subcampo. Logo, esse mesmo mecanismo de constituição e unificação torna-se um instrumento de violência simbólica ao operar a imposição inconsciente de um consenso, omitindo-se as lutas passadas e em curso e omitindo-se como objeto em disputa. Pode-se dizer, ainda, que a unificação e universalização, necessárias para a construção de um campo social e de um mercado de simbólico, somente exercem seu efeito mediante violência simbólica que omite em certa medida as disputas no próprio campo.

\section{Afirmação da existência objetiva e simbólica do movimento CTS}

Para compreender o movimento CTS, assim como qualquer outro espaço de produção simbólica, é preciso analisar a situação na qual e contra a qual ele se constituiu e tornou-se real (Bourdieu, 2010a). Assim, mais do que "narrar" uma sucessão de "fatos" históricos, analisar a história é perceber a ação histórica enquanto força simbólica. Esta, se impõe em dois estados da história: uma história no estado objetivado, isto é, acumulada nos objetos e nas coisas pela ação do tempo (livros, teorias, máquinas, procedimentos, etc.); e uma história incorporada interiorizada e exteriorizada pelos agentes na forma de habitus. Esses dois estados permitem à história sobreviver no tempo e atuar sobre os agentes ao mesmo tempo em que eles a atualizam e a transformam em ação histórica por meio de investimentos individuais e coletivos. Trata-se de uma dialética entre a "história feita coisa" e a "história feita corpo" que, por uma espécie de cumplicidade dóxica, construtora de um senso prático, rege as representações e as tomadas de posição e ação tanto no espaço social quanto no espaço de lutas (Bourdieu, 2010a, p. 83).

Uma função implícita na referência recorrente à história de um determinado campo é a de afirmar e reafirmar a existência do campo como tal, da forma como é visto e percebido pelos agentes que nele atuam. Dos 9 trabalhos analisados, 8 destacam em algum momento as razões ou motivações consagradas historicamente, que desencadearam a constituição do movimento CTS. Portanto, a afirmação da existência 
objetiva e simbólica do movimento CTS está no próprio fato de que há "uma história a ser contada" e a ser defendida em relação aos demais campos de produção simbólica. Evidencia-se e defende-se a revolução simbólica que provocou a emergência do campo bem como a visão de mundo que a caracteriza e a diferencia dos demais campos de produção simbólica. A partir daí, são destacados sucessivos acontecimentos que permitiram a emergência e relevância dos problemas denunciados e enfrentados pelos agentes do campo.

Dentro da literatura dominante no Subcampo Brasileiro de Pesquisa em Ensino de Ciências CTS, o final da $2^{\text {a }}$ Guerra Mundial é apontado como o primeiro marco histórico importante que desencadeou uma série de eventos sucessivos que culminariam na construção dos ideais do movimento CTS. Mais especificamente, o efeito devastador provocado pelas explosões das bombas nucleares nas cidades de Hiroshima e Nagasaki mostrou ao mundo o poder que o ser humano havia alcançado por meio da ciência e da tecnologia. Paradoxalmente, no período denominado pós-guerra, tal demonstração de poder levou à disseminação de uma percepção encantada da ciência e da tecnologia, uma vez que, afinal, ambas se mostraram tão eficazes em combater o "mal" que avançara sobre as sociedades ocidentais (Bazzo, Von Linsingen \& Pereira, 2003; Santos \& Mortimer, 2002).

Desse modo, foi estabelecido um "contrato social" alicerçado em uma concepção essencialista e triunfalista da ciência e da tecnologia (Auler, 2002). Tal contrato é apresentado na literatura dominante sob a forma de um modelo tradicional/linear de progresso social, desenvolvimento e inovação, baseado na crença da neutralidade da ciência e da tecnologia (Cerezo, 2004; Pinch \& Bijker, 1984). A ciência, até então caracterizada como uma entidade abstrata, neutra e verdadeira de compreensão da natureza, atuaria na sociedade por meio de suas "aplicações práticas", caracterizadas por tecnologias. As tecnologias, por sua vez, deveriam ser postas a serviço da economia, que estaria encarregada de empregá-las para a promoção do bem-estar social (Bazzo, 1998). Essa concepção de progresso levou a um aumento expressivo nos investimentos em pesquisas científicas, que nos Estados Unidos, passou de 2,8 bilhões para 12,6 bilhões de dólares por ano, no período de 1953 a 1965 (Dixon, 1976).

O pioneirismo soviético na exploração espacial com o lançamento do primeiro satélite artificial, o Sputinik em 1957, e a ida do primeiro homem ao espaço, Yuri Gagarin em 1961, lançaram as primeiras dúvidas sobre a suposta eficácia do modelo desenvolvimentista até então defendido (Auler, 2002; Bazzo, Von Linsingen \& Pereira, 2003). Entretanto, tais dúvidas não recaíram diretamente na ciência e na tecnologia, e sim no ensino praticado sobre elas. $\mathrm{O}$ ensino de ciências foi então caracterizado como obsoleto e demasiado distante da "ciência praticada pelos cientistas", de modo que novos investimentos precisavam ser feitos. Nessa linha, alguns projetos de renovação curricular foram elaborados com o objetivo de formar cada vez mais cientistas e entusiastas da ciência e da tecnologia: PSSC (Física), CBA (Química), BSCS (Biologia), SMSG (Matemática) etc. Tais projetos eram caracterizados por uma forte abordagem experimental e reconhecidamente destinados para "alunos mais academicamente 
orientados" (Cruz \& Zylbersztajn, 2001, p. 175).

A crença coletiva, constitutiva da doxa, de que o questionamento ao projeto de sociedade até então adotado é uma necessidade, é construída mediante o elencar de episódios históricos que destacam os impactos da ciência e da tecnologia sob os moldes do contrato social até então estabelecido e empregado. Logo, os acontecimentos históricos ocorridos ao longo das décadas de 1950 e 1960, destacados na literatura do subcampo, evidenciam diversos problemas sociais que são atribuídos ao desenvolvimento científico e tecnológico: a degradação ambiental proporcionada tanto acidentalmente (vazamentos em usinas nucleares, em petroleiros) quanto intencionalmente (exploração desregulada de recursos naturais); efeitos colaterais irreversíveis provocados pelo uso de medicamentos (como a talidomida); o desenvolvimento de armas gradativamente mais destrutivas proporcionados pela corrida armamentista EUA X URSS; as crises econômicas do capitalismo, sobretudo as sucessivas crises do petróleo; etc. Todos esses fatores aliados ao reconhecido fracasso das reformas curriculares educacionais até então empregadas que negligenciavam uma formação mais ampla que considerasse contextos sociais relevantes aos alunos, levou à emergência de movimentos sociais de contestação, contraculturais, ecologistas, pacifistas na Europa e nos Estados Unidos. Tais movimentos evidenciaram a latente quebra do contrato social anteriormente estabelecido e amplamente criticado pela literatura CTS (Bazzo, Von Linsingen \& Pereira, 2003).

Apesar da literatura dominante no subcampo brasileiro indicar que os questionamentos ao modo de produção da ciência e da tecnologia, nos moldes do contrato social estabelecido após a 2a Guerra Mundial, terem se iniciado entre as décadas de 1960 e 1970 (Amorim, 1997; Auler, 2002; Santos \& Mortimer, 2002), alguns escritos de Robert K. Merton ${ }^{3}$ indicam a existência de questionamentos anteriores, entre as décadas de 1930 e 1940. Em um texto datado de 1938, Merton sinaliza algumas características sobre esses questionamentos levantados sobre a ciência e a sua legitimidade, as chamadas hostilidades à ciência:

A hostilidade à ciência pode surgir de, pelo menos, dois conjuntos de condições, embora os sistemas concretos de valores - humanitários, econômicos, políticos, religiosos sobre os quais se baseia possam variar consideravelmente. O primeiro conjunto envolve a conclusão lógica, embora não necessariamente correta, de que os resultados ou os métodos da ciência são hostis à satisfação de valores importantes. O segundo consiste largamente de elementos não lógicos. A ele subjaz o sentimento de incompatibilidade entre os sentimentos incorporados no éthos científico e aqueles encontrados em outras instituições. Sempre que esse sentimento é desafiado, ele é racionalizado. Ambos os conjuntos de condições subjazem, em graus variados, às revoltas atuais contra a ciência. (Merton, 2013a, p. 160)

\footnotetext{
3 A tese de doutorado de Robert K. Merton - Science, Technology and Society in Seventeenth Century England (1938) - é considerada um marco na sociologia da ciência. Nesse trabalho são apresentadas as primeiras análises que tentam estabelecer explicações sociológicas sobre o êxito no surgimento da ciência moderna no contexto da Inglaterra do séc. XVII. Merton foi a referência central na área da sociologia da ciência até a publicação de As Estruturas das Revoluções Científicas de Thomas Kuhn, em 1962, e o surgimento do Programa Forte na sociologia do conhecimento (Bloor, 2009) durante a década de 1970. (Marcovich \& Shinn, 2013; Shinn \& Ragouet, 2008)
} 
Em outro trecho datado de 1942, Merton sinaliza que tais questionamentos começam a ocupar certos espaços na estrutura social:

A revolta contra a ciência, que então parecia tão improvável, já que concernia apenas a tímidos acadêmicos, que ponderavam todas as contingências, apesar de remotas, chama agora a atenção tanto do cientista como do homem leigo. A contaminação local de anti-intelectualismo ameaça tornar-se epidêmica. [...] Os incipientes ataques atuais à integridade da ciência levaram os cientistas a reconhecer sua dependência de tipos particulares de estrutura social. Manifestos e pronunciamentos de associações de cientistas devotam-se às relações entre a ciência e a sociedade. (Merton, 2013b, p. 181)

Além de sinalizar a existência de questionamentos à ciência até mesmo anteriores à 2a Guerra Mundial, em particular o segundo fragmento indica, ainda, que tais questionamentos foram construídos inicialmente no campo acadêmico, o que contrasta com algumas análises históricas dominantes no Subcampo Brasileiro de Pesquisa em Ensino de Ciências CTS, que afirmam "o caráter militante e menos acadêmico, características do início do movimento CTS” (Auler, 2002, p. 28). Apenas Amorim (1995), em um outro trabalho, sinaliza para questionamentos à ciência e à tecnologia, anteriores à $2^{\text {a }}$ Guerra Mundial:

Historicamente, a proposição das ideias sobre a relação entre Ciência/Tecnologia/ Sociedade provavelmente pode ser encontrada nos anos 30, especialmente com o trabalho de Desmond Bernal, como autor do livro The social function of Science. A tese de Bernal, grosseiramente simplificada, era que a ciência não era uma atividade puramente neutra, cerebral, ou cultural isolada da estrutura sócio-econômica da sociedade, mas se influenciava, ou realmente era dirigida por esses fatores mais o poder político ou econômico. (Amorim, 1995, p. 15)

Logo,oselementosindicadosatéaquicomoprecursoreshistóricosqueantecederam o surgimento do movimento CTS destacados, em maior ou menor detalhamento, ao longo da literatura dominante e que evidenciam uma aparente e intencional linearidade presente nessa história, visam construir um cenário histórico em que o desenvolvimento de suas ideias e prerrogativas tornem-se inevitáveis e urgentes, portanto, necessárias. A presença recorrente da história de origem do movimento CTS, portanto, visa tornar importante a existência do subcampo CTS brasileiro justificando-o no âmbito social. Sob a ótica da teoria do campo, a sinalização recorrente que vincula a origem do CTS aos movimentos sociais emergentes na década de 1960, não possui outro objetivo senão a intenção de buscar maior legitimidade à existência e consolidação do subcampo, uma vez que os ideais defendidos passam a ser vistos como um "anseio da sociedade", no lugar de apenas mais uma proposta acadêmica. Aqui temos um esboço inicial da construção da illusio do subcampo. Todos esses elementos são mobilizados para se criar a ilusão responsável por transformar as representações emergentes e originárias da revolução simbólica em curso como algo evidente, algo óbvio, necessário para sublimar o trabalho de conversão coletiva e exercer o efeito de violência simbólica necessária para tornar uma visão específica de mundo a visão verdadeira do mundo (Bourdieu, 2010a). Trata-se, 
portanto, de uma aposta, consciente ou não, realizada no interior da disputa científica.

A história dominante, sob esse ponto de vista, é um problema político-científico uma vez que tal construção possibilita a existência e persistência do subcampo no espaço social e a sua consequente transformação. Uma característica importante desse problema político-científico é a apresentação dos problemas denunciados e enfrentados pelo subcampo como um problema evidente e "real", tratado como um problema dado, em oposição à ideia do objeto e problema construídos, reafirmando, novamente, a existência do subcampo como uma necessidade. Como ocorre em qualquer campo de produção simbólica, o subcampo sobrevive ao construir parte da "realidade" de acordo com os seus interesses, ao mesmo tempo em que estabelece "a verdade" legítima sobre ela. Logo, o cenário histórico construído torna o questionamento à concepção imposta à ciência e à tecnologia por meio do "contrato social" que fora estabelecido no período pós-guerra, uma exigência sentida por diversos segmentos sociais. Esse questionamento levantou "a necessidade de revisar a política científico-tecnológica de carta branca e, com ela, a concepção de ciência e tecnologia e de sua relação com a sociedade" (Cerezo, 2004, p. 14).

\section{O contrato social}

A crítica à noção de "contrato social" é o ponto de partida para a revolução simbólica com o intuito de empreender uma inversão de valores para a criação de uma outra representação para a ciência e a tecnologia. O contrato social para a ciência e tecnologia é referenciado explicitamente em três dos trabalhos analisados (Auler \& Bazzo, 2001; Auler, 2002; Auler \& Delizoicov, 2006), mas suas principais ideias e críticas estão presentes em todos os demais trabalhos que fazem parte do corpus de análise. Os trabalhos abordam principalmente a oposição entre o modelo tecnocrático de gestão e o modelo de participação pública que propõem papéis distintos a serem desempenhados pelo cidadão que sobrevive em sociedades marcadamente influenciadas, modeladas e estruturadas pelos fatos e artefatos científicos e tecnológicos. Os emergentes questionamentos ao desenvolvimento científico e tecnológico, aos seus modos de produção e de legitimação na e perante a sociedade, somente puderam se destacar porque a própria ciência e a tecnologia se fortaleceram e conquistaram considerável importância com a instituição do contrato social (Dixon, 1976).

O contrato social permitiu que a ciência e a tecnologia se tornassem oficialmente uma política de Estado, uma vez que o Estado tem a função de apropriar-se dos diferentes tipos de capitais necessários para manter a sua autonomia e o seu monopólio sobre o exercício da violência física e simbólica legítima e, simultaneamente, inculcar a necessidade pela manutenção da ordem social vigente (Bourdieu, 2010a; 2014). O modelo linear de desenvolvimento e inovação (Pinch \& Bijker, 1984) e o mito do benefício infinito (Cerezo, 2004) nada mais são, senão, estratégias mais ou menos intencionais e mais ou menos inconscientes de buscar apoio social e, consequentemente, maior legitimidade no espaço social que justificasse o investimento do Estado. O Estado, 
segundo Bourdieu, atua "como uma espécie de banco de capital simbólico, garante todos os atos de autoridade, atos arbitrários, mas que não são vistos como tais" (2010b, p. 113), de modo que associar-se a ele é apropriar-se de toda a sua autoridade capaz de gerar discursos oficiais dotados de uma eficácia simbólica única.

Ao criticar o contrato social até então estabelecido, o movimento CTS visa promover uma inversão de valores atribuindo o papel decisório para o cidadão. Tornando a participação pública em decisões envolvendo ciência e tecnologia uma necessidade para a sociedade e para a manutenção da ordem social, assim como o desenvolvimento científico e tecnológico o foram tornados no período pós-guerra, os defensores do movimento CTS também buscaram sua legitimidade junto à sociedade que justificasse, também, o investimento do Estado. Assim, o movimento CTS procurou dotar-se da autoridade do Estado ao buscar o estabelecimento de um novo contrato social a partir de um trabalho de conversão coletiva que visou, simultaneamente, tornar a crença dominante em descrença e apresentar uma nova crença que correspondesse às expectativas criadas pelas críticas lançadas ao modelo anterior.

Um indício interessante dessa disputa pela atenção e investimento do Estado pode ser visto no contexto norte-americano acerca dos investimentos governamentais sobre o currículo de ensino de ciências naturais. Na década de 1960, a National Science Foundation (NSF) financiou diversas reformas curriculares, entre essas o projeto de ensino de Física do Physical Science Study Committee, conhecido pela sigla PSSC (Alves-Filho \& Pinheiro, 2012). Devido ao contrato social até então estabelecido, o ideal para a sociedade e, por isso, a responsabilidade do Estado, era estabelecer uma educação científica direcionada para a formação de cientistas e engenheiros capazes de alavancar o desenvolvimento e o progresso social por meio do avanço da ciência e da tecnologia. $\mathrm{Na}$ medida em que a revolução simbólica promovida pelo movimento CTS conseguiu construir e impor novos valores para a educação científica, mobilizando instrumentos simbólicos tais como o apoio popular para a deliberação pública dos rumos da ciência, partindo da crítica contra a eficácia dos sistemas tecnocráticos e a denúncia da ineficiência dos projetos curriculares anteriores (Cruz \& Zylbersztajn, 2001), anos mais tarde foram obtidos investimentos governamentais para o desenvolvimento de currículos em CTS, tais como o já citado Project Synthesis, também financiado pela NSF. Portanto, uma vez que a função do Estado é garantir aos cidadãos acesso aos meios culturais necessários para o exercício de seus direitos civis (Bourdieu, 2010b; Bourdieu, 2014), o movimento CTS conseguiu operar sua revolução simbólica ao impor a necessidade de políticas públicas que fornecessem instrumentos de participação para os cidadãos tomarem decisões, e a necessidade de uma educação científica diferenciada que possibilitassem essas tomadas de decisões de forma crítica e consciente.

Devemos lembrar, ainda, da mesma forma com que se tornam possíveis as revoluções simbólicas em qualquer outro campo, essa imposição de novos valores e representações do mundo social ao campo das políticas públicas e ao campo educação em ensino de ciências somente ocorre quando os agentes que os defendem conseguem 
mobilizar recursos dentro e fora do campo simultaneamente, de acordo com interesses específicos, mesmo esses interesses não sendo nunca totalmente evidentes e definidos para esses agentes, muito menos as estratégias necessárias para obtê-la (Bourdieu, 2010b). A revolução simbólica, no momento "pré-revolucionário" (adotando-se, por empréstimo, essa noção kuhniana), nada mais é senão um investimento de alto risco, uma aposta, que nada tem de evidente quando comparada à história correntemente contada e reforçada no e pelo campo e que, somente, se torna realidade mediante o trabalho de universalização dos interesses específicos tidos na base da crença particular levada adiante pelos revolucionários. Trata-se do trabalho de universalização de uma illusio específica e, consequentemente, o ocultamento permanente da doxa no subcampo.

\section{A illusio e a doxa}

O interesse é a condição fundamental para o funcionamento de um campo uma vez que permite tornar os objetivos do mesmo algo pelo qual vale a pena se investir e lutar. A illusio torna a luta pelo campo interessante e, portanto, real e desejável. O “jogo merece ser jogado" porque os resultados, os lucros simbólicos, são vistos como interessantes por aqueles dotados de esquemas práticos de percepção e ação (habitus) capazes de reconhecer os lucros, dar valor a eles, e estar predispostos a fazer uma aposta, um investimento, um lance no jogo. Por ser um princípio fundamental para o campo, existem e persistem no espaço social tantos campos quanto illusiones possíveis de se constituir e persistir historicamente. Trata-se, portanto, de uma ilusão capaz de mobilizar os agentes, resultante de uma determinada construção histórica e instituída arbitrariamente, mas que somente pode se fazer conhecer através da história que a omite enquanto escolha arbitrária (Bourdieu, 2004c).

Nos campos de produção simbólica relativamente autônomos, tais como o campo científico, a illusio adquire a aparência de um interesse desinteressado e de um interesse pelo desinteresse. Isto é, o interesse científico consiste em uma forma tão particular de interesse específico que, quando apreciado por alguém não dotado do habitus específico necessário para reconhecê-lo, este lhe parece completamente ausente de interesse, plenamente gratuito. Dito de outra forma, o campo científico consiste em um espaço onde o desinteresse é bem visto e apreciado, é compensado e recompensado, o que faz com que as estratégias empregadas pelos agentes nele em disputa, movidos por seus interesses específicos, sejam de duplo sentido: luta-se, investe-se, aposta-se pelo progresso do campo, da ciência, do conhecimento e para se obter uma posição mais privilegiada na estrutura ao ser reconhecido pelo progresso alcançado (Bourdieu, 2004a).

A literatura dominante do Subcampo Brasileiro de Pesquisa em Ensino de Ciências CTS está permeada pelas reconstruções históricas interessadas que reforçam a todo instante a illusio defendida pelo campo e que o coloca permanentemente em luta:

Os trabalhos curriculares em CTS surgiram, assim, como decorrência da necessidade de formar o cidadão em ciência e tecnologia, o que não vinha sendo alcançado 
adequadamente pelo ensino convencional de ciências. (Santos \& Mortimer, 2002, p. 3 grifos nossos)

Trata-se de ir além dos objetivos centrados nos conteúdos e nos processos da ciência marcados por epistemologias internalistas. A educação em ciência passa também a ser educação sobre ciência. A educação científica só tem sentido no contexto de uma educação para a cidadania. $\mathrm{O}$ processo pedagógico, agora, não se limita à sala de aula. $\mathrm{O}$ meio circundante, a comunidade passa a integrar o contexto educacional. (Auler, 2002, p. 11 grifos nossos)

Esta maneira de encarar a ciência e seu ensino, assume a necessidade de envolver o mundo dos participantes (alunos e professores) e de incorporar e relacionar as suas preocupações, para com isso aumentar a sua capacidade de resolver problemas. Quando se considera a forma cada vez mais poderosa através da qual a ciência e a tecnologia influenciam a vida cotidiana, torna-se clara a necessidade de uma educação científica que permita o envolvimento com temas decorrentes dessa influência, possibilite julgamentos, sugira ações práticas e aplicações locais e que seja rica em valores. (Cruz \& Zylbersztajn, 2001, p. 172 grifos nossos)

Esse interesse do subcampo CTS, que repousa na promoção de uma formação científica cidadã aos estudantes, capaz de fomentar uma postura crítica aos problemas científicos e tecnológicos de forte impacto social, além de mobilizar os agentes atuantes na estrutura em questão, dando-lhes a ilusão, a crença, o sentido do jogo e que motivam as suas aspirações e ambições pessoais (dependentes elas próprias de sua posição na estrutura das lutas simbólicas), também omitem aquilo que é percebido como evidente, de tal modo que é simplesmente mantido fora de discussão: a doxa.

Essa espécie de consenso inconsciente, invisível e inquestionável, a doxa, situase por detrás das dissensões e embates protagonizados pelos agentes antagonistas no campo. A submissão dóxica consiste numa espécie de censura tácita, admitida de forma inconsciente por todos os que se permitem participar das lutas no campo, porque estão comprometidos com o campo e, portanto, são coniventes com a submissão. Mais do que uma regra a ser seguida, a doxa é aceita tacitamente pelo agente a partir do momento em que se reconhece e se aceita como legítima a illusio do campo, passando a estar comprometido com o próprio funcionamento do campo e com os seus fundamentos.

A doxa do Subcampo Brasileiro de Pesquisa em Ensino de Ciências CTS, da mesma forma que acontece nos demais campos de produção simbólica, encontra-se sublimada em meio aos produtos e às discussões construídas e estabelecidas pelos agentes. Ela é, ao mesmo tempo, o que há de mais evidente e de mais velado no campo, uma vez que a simples possibilidade de questionamento a essa "verdade" escondida em meio as lutas, põe em risco a própria existência do campo. Ao aceitar-se a illusio do Subcampo Brasileiro de Pesquisa em Ensino de Ciências CTS, aceita-se, implicitamente, a possibilidade de uma formação científica orientada para os cidadãos. Nenhum dos agentes posicionados no subcampo se pergunta: “É realmente possível formar cientificamente um cidadão?”. Este é um questionamento proibido no interior do subcampo e em meio às suas discussões 
porque uma simples resposta negativa colocaria em risco toda a sua estrutura, que sustenta e garante os investimentos e os lucros simbólicos dos agentes. Assim, fazem parte integrante da doxa toda a (re)construção histórica que impõe como necessária a formação científica de cidadãos e que omite a discussão sobre a real possibilidade de uma formação cidadã em/sobre ciências. Logo, questionamentos dos agentes no subcampo, sejam dominantes sejam dominados, estejam eles empregando estratégias de conservação ou estratégias de subversão, sempre giram em torno dos problemas e metodologias associadas à melhor maneira de se formar cidadãos críticos das relações CTS presentes no meio em que vivem.

\section{Problemas e metodologias dominantes}

Tratando-se de um interesse intrínseco às configurações do subcampo, a illusio tende a mobilizar os agentes em torno dos problemas capazes de gerar um alto lucro simbólico, isto é, o reconhecimento de seus pares concorrentes e o prestígio de uma posição mais privilegiada na estrutura das lutas travadas no subcampo. Logo, aquilo que é conhecido e reconhecido como importante e interessante (no duplo sentido), tende a ser assim reconhecido pelos demais agentes do campo, pois trata-se de algo que fará com que a produção simbólica seja apreciada e considerada importante pelos demais concorrentes, lançando-se luz sobre seu produtor, destacando-o dos demais (Bourdieu, 1983).

Uma vez que a illusio, que mobiliza o subcampo e estabelece a busca pela formação de cidadãos aptos a reconhecerem as complexas relações CTS estabelecidas em seu meio social, é reconhecida e apropriada pelos agentes, o principal objeto em disputa no subcampo CTS, pelo qual se busca uma resposta é: "O que significa formar cientificamente um cidadão?”. Aquele que conseguir dar o melhor encaminhamento a tal pergunta, ou fazer os demais agentes reconhecerem o seu encaminhamento como o mais adequado ou ajustado, ou ainda, aquele que conseguir fornecer uma resposta criativa e inesperada, portanto original, e que seja assim reconhecida pelos demais agentes do campo, tende a se posicionar nos locais mais privilegiados da estrutura das lutas simbólicas - torna-se um dominante.

As construções históricas orientadas pela illusio e expostas pela literatura dominante no Subcampo Brasileiro de Pesquisa em Ensino de Ciências CTS, destacam um ideal de cidadão particular que é amplamente valorizado e almejado. Este cidadão deve possuir capacidades específicas como tomar decisões informadas e responsáveis sobre problemas e controvérsias sociais envolvendo ciência e tecnologia e empreender ações conscientes orientadas para a solução desses problemas (Amorim, 1997; Auler \& Bazzo, 2001; Auler, 2002; Bazzo, 1998; Cruz \& Zylbersztajn, 2001; Santos \& Mortimer, 2002). Logo, de acordo com o pensamento dominante no subcampo CTS, formar cidadãos críticos das relações CTS significa desenvolver estratégias de ensino e aprendizagem capazes de fomentar a construção de conceitos e o desenvolvimento de habilidades e valores tidos e defendidos pelo próprio subcampo como interessantes e pertinentes para 
a atuação democrática na sociedade.

E qual seria a melhor metodologia para se formar cidadãos capazes de tomar decisões responsáveis e ações conscientes? Embora seja desejável que as metodologias propostas pelos agentes do subcampo sejam aceitas pelos demais agentes como soluções infalíveis e que sejam postas a funcionar integralmente, quase que como um roteiro, ou uma fórmula mágica, o que acarretaria o prestígio do reconhecimento no subcampo, os agentes jamais admitem tal desejo, seja pelo fato de se tratar de um subcampo interior ao campo educacional que há muito abole a mera aplicação mecânica de modelos educacionais desconsiderando-se as especificidades de cada contexto, seja pela própria dinâmica de funcionamento de um campo, que impede a aceitação pura e simples dos produtos simbólicos construídos pelos concorrentes, pelo simples fato de existir uma luta pela definição da verdade desses produtos. Entretanto, algumas metodologias são consagradas pela literatura dominante por serem recorrentemente sinalizadas nas reconstruções históricas do movimento CTS, tais como: a abordagem temática e interdisciplinar; o tratamento de problemáticas reais, abertas e próximas do contexto dos alunos; o debate de ideias; a abordagem de controvérsias; a valorização do pensamento divergente; a utilização de simulações e de "jogos de papeis"; atividades de tomada de decisão; a construção de modelos e de artefatos tecnológicos; a abordagem de fatos da história da ciência e da tecnologia.

Trata-se de metodologias que visam explorar os aspectos ambientais, políticos, econômicos, éticos, sociais e culturais que permeiam a vivência dos alunos na sociedade. Além disso, tais metodologias evidenciam a importância de trabalhos e a organização dos alunos em pequenos grupos, o incentivo à aprendizagem cooperativa; discussões centradas nos estudantes e a ação comunitária como meios para gerar motivação e o cultivo de conhecimentos, habilidades e valores apontados como necessários para a formação cidadã. Ao apresentar aqui todas essas denominações de estratégias pedagógicas que são encontradas na literatura dominante, pode-se pensar que há uma variedade de metodologias disponíveis e em iguais condições de disputa no subcampo. Essa conclusão aparente se mostra equivocada quando se percebe que há convergências implícitas em todas as metodologias propostas, as quais tendem a privilegiar o trabalho coletivo e a tomada de decisões. As diferentes nomenclaturas dadas a essas metodologias nada mais são que tentativas de diferenciação na estrutura das lutas das pesquisas CTS no país.

Os problemas e metodologias historicamente consagradas e apresentadas como dominantes exercem um poder simbólico sobre os agentes e sobre as estruturas, tanto objetivas quanto incorporadas, pois permitem uma construção específica da realidade estabelecendo uma "ordem gnosiológica". Eles produzem uma percepção homogênea do universo simbólico que torna possíveis as concordâncias estabelecidas sobre determinados objetos. Da mesma forma que os trabalhos sinalizados por Chrispino et al. (2013) são percebidos como "leitura obrigatória" no subcampo, sendo reconhecidos por sua pertinência o que, consequentemente, torna seus autores agentes dominantes, 
capazes de deformar o espaço à sua volta e demarcar posições no campo em relação à sua, os problemas e metodologias dominantes também se impõem aos agentes que, igualmente, devem se posicionar em relação a elas e, ao mesmo tempo, contra elas.

A violência simbólica exercida pelos problemas e metodologias dominantes as faz atuar, portanto, como requisitos de entrada no campo. Os agentes devem, então, incorporá-los à sua prática científica ou assumir determinada posição em relação a eles, de modo que, qualquer que seja a alternativa adotada, ela evidencia a devida apropriação dos conceitos e práticas dominantes, dando, assim, aos agentes o direito de participar da luta científica de forma legítima. Trata-se de bens simbólicos que são implicitamente exigidos tanto pelas estruturas objetivas quanto pelas estruturas incorporadas, pelos agentes e para os agentes no campo. Tais bens simbólicos fazem parte da definição tacitamente aceita como verdadeira, e são estabelecidos como a ordem vigente no campo, que devem ser compartilhados e adotados ou devem ser levados em conta caso se pretenda questionar a ordem estabelecida - no caso, operar uma revolução no campo. De qualquer forma, a energia social historicamente acumulada e, incessantemente, firmada e afirmada por meio de referências históricas à sua gênese, se conserva quando esses bens simbólicos se tornam, obrigatoriamente, objetos de dissensão e disputa, portanto, permanentemente presentes no campo e sobre os quais os agentes devem se ocupar na busca por uma posição mais privilegiada na estrutura das lutas. Para o tratamento desses objetos, os agentes, dependendo da posição que ocupam na estrutura e da trajetória anterior que os levou a ocupar determinada posição no presente, lançam mão de estratégias mais ou menos conscientes, com o objetivo de alcançar uma melhor posição em meio às lutas simbólicas. Tais estratégias levam a uma relativa diferenciação dos agentes na estrutura.

\section{Elementos de diferenciação na estrutura}

O campo científico é o local onde todas as práticas sociais são direcionadas para a aquisição de autoridade científica e em que o reconhecimento consiste em se fazer "um nome próprio, um nome conhecido e reconhecido" dotado de visibilidade dentro do campo, ou seja, diferenciar-se do fundo indiferente e comum, tornando-se referência destacada e diferenciada na estrutura (Bourdieu, 1983, p. 132). Com esse objetivo em mente, cada agente desenvolve estratégias relativamente diferenciadas, dependendo da posição que ocupa em determinado momento, do estado das lutas em curso no campo e da percepção que esse determinado agente possui desse estado das lutas em curso.

Logo, as estratégias empregadas pelos agentes refletem sobre as reconstruções históricas dominantes aqui analisadas, uma vez que, por desempenhar papel simbólico importante nas lutas e no estabelecimento do campo, essas reconstruções também são, de modo inconsciente, incorporadas às estratégias de diferenciação na estrutura na busca por autoridade científica. A autoridade científica é obtida através do acúmulo de capital científico, que é o princípio diferenciador dos agentes e das estratégias na estrutura do campo. No campo em questão, o Subcampo Brasileiro de Pesquisa em Ensino de Ciências 
CTS, são identificados dois tipos de capitais: o capital cultural (ligado especificamente às contribuições feitas às problemáticas enfrentadas pelo campo) e o capital social (ligado à presença em cargos burocráticos que exercem influência no campo) (Ribeiro, 2015).

$\mathrm{Na}$ literatura dominante no subcampo CTS, as reconstruções históricas sinalizam para elementos diferenciadores dos agentes de acordo com a estrutura do capital acumulado e almejado. Nas caracterizações históricas apresentadas por agentes com inclinações ao acúmulo de capital social, percebe-se uma evidente valorização e importância dos escritos e trabalhos estrangeiros sobre CTS, sobretudo na chamada "vertente norte-americana" do movimento CTS. As reconstruções históricas proporcionadas por esses agentes possuem como características um uso extenso de citações de literaturas estrangeiras, obras em sua maioria disponíveis somente em língua estrangeira e, relativamente, de difícil acesso. Apesar da primazia dada à vertente norteamericana, alguns elementos da "vertente europeia" do movimento CTS são elencados, apenas a título de ilustração, estando praticamente toda a discussão marcadamente realizada sobre os autores norte-americanos.

Por sua vez, as reconstruções históricas apresentadas por agentes caracterizados pelo acúmulo de capital cultural apresentam uma preocupação em evidenciar a existência do pensamento local desenvolvido sobre as relações CTS, denominado de Pensamento Latino-americano CTS - PLACTS (Dagnino \& Thomas, 2002; Vaccarezza, 2004). Além disso, as caracterizações históricas levam em consideração as contribuições produzidas no contexto nacional de pesquisa em ensino de ciências CTS e uma relativa aproximação às pesquisas em ensino de ciências CTS produzidas em países europeus como Espanha e Portugal.

Essas sutis diferenças percebidas nas reconstruções históricas dominantes realizadas no subcampo CTS sinalizam para o arbitrário presente nas escolhas históricas que as próprias reconstruções se esforçam por omitir. As opções feitas, condicionadas pelo "sentido do jogo" incorporado ao longo de uma trajetória particular na história das lutas, são dependentes elas próprias das posições ocupadas pelos agentes e do estado das lutas (passado e presente) no interior da estrutura. Tais posições permitem enxergar certas coisas e não enxergar, ou não querer enxergar, outras. Portanto, elas resultam em opções que tornam "reais" e existentes determinadas realidades e tornam ocultas e inexistentes, logo irreais, outras realidades não perceptíveis. Esse ocultamento existente no arbitrário das escolhas feitas, capaz de tornar verdadeiras realidades específicas que se impõem a todo instante aos agentes em disputa no campo, é elemento constitutivo da violência simbólica que se exerce sobre todo o campo, com o consentimento tácito tanto daqueles que a exercem, quanto daqueles que a sofrem, tornando-a, assim, legítima e "verdadeira" (Bourdieu, 2004a).

\section{Falsos problemas}

Por fim, além de desvelar alguns mecanismos de dominação presentes no campo e promover uma ruptura com a noção ingênua de senso comum sobre a história - 
caracterizada aqui por "historicismo espontâneo" - e que contribui para a disseminação acrítica de diversos elementos e instrumentos de dominação aqui abordados, a análise da literatura dominante pode, ainda, apontar para alguns princípios de visão e divisão que, igualmente espontâneos e ingênuos, podem resultar em construções equivocadas e evidenciar falsos problemas e classificações (Bourdieu, 2004a). Um destes falsos problemas que acarretam falsas classificações consiste na distinção do movimento CTS em duas vertentes, caracterizadas por sua origem geográfica, sendo atribuída a uma dela a denominação de vertente/tradição europeia e à outra de vertente/tradição americana:

Enquanto a primeira premissa resume os resultados da pesquisa acadêmica na tradição CTS de origem europeia, centrado nos estudos dos antecedentes sociais da mudança em ciência-tecnologia, a segunda recolhe os resultados de outra tradição mais ativista, com origem nos EUA, centrada mais nas consequências sociais e ambientais da mudança científico-tecnológica e nos problemas éticos e reguladores suscitados por tais consequências. (Bazzo, Von Linsingen \& Pereira, 2003, p. 127)

O posicionamento americano, pelos problemas sociais com que nos deparamos, é mais produtivo, pois tem um caráter mais prático por implicar a presença de uma proposta mais educativa e ética com especial interesse na democratização dos processos de tomada de decisões em políticas tecnológicas e ambientais. A escola europeia, por sua vez, é fortemente enraizada na tradição acadêmica, dando mais valorização à ciência e ao seu desenvolvimento para secundariamente ocupar-se da tecnologia. (Bazzo, 1998, p. 223)

A falsa dicotomia imposta pelas reconstruções históricas dominantes no subcampo invoca um falso problema ao insistir na dualidade vertente europeia/vertente americana, uma "mais acadêmica" e outra "mais ativista", que opera distinções estigmatizadas, estigmatizadoras e, portanto, redutoras dos produtos simbólicos produzidos pelo movimento CTS. Apesar do CTS ser um "movimento" cuja gênese se deu no espaço acadêmico - conforme sinalizado principalmente na categoria "Afirmação da existência objetiva e simbólica do movimento CTS” e que aqui é defendida - a negação insistente das citações acima da vertente europeia, supostamente "enraizada na tradição acadêmica" e a preferência declarada à vertente americana, supostamente "mais ativista" pode ser interpretada, claramente, como um retorno à tentativa de vinculação aos movimentos sociais que garantiram autoridade e legitimidade ao movimento CTS em sua origem.

As investigações realizadas pela chamada vertente europeia, generalizada por ser "centrada nos estudos dos antecedentes sociais da mudança em ciência-tecnologia" realmente abordam o desenvolvimento e a consolidação de fatos e artefatos científicos e tecnológicos, porém apontam instrumentos para a renegociação desses produtos pelos cidadãos interessados, o que tem importante impacto na avaliação de suas consequências e de possíveis alternativas (Latour, 2011). Outras pesquisas abordam o trabalho de movimentos sociais na discussão da ciência e da tecnologia como, por exemplo, os estudos realizados por Collins e Pinch (2010a; 2010b) que analisam o desempenho de grupos ativistas organizados e mobilizados em controvérsias científico-tecnológicas 
ligadas ao teste de medicamentos para o tratamento da AIDS, evidenciando a forma com que esse engajamento proporcionou uma renegociação da relação médico-paciente nas pesquisas e testes de novos medicamentos. Por fim, a afirmação de que essa tradição atribui um papel secundário à tecnologia é refutada por diversos trabalhos que se ocupam em analisar controvérsias e reconstruções históricas envolvendo artefatos e sistemas tecnológicos (Callon, 1987; Collins \& Pinch, 2010a; Collins \& Pinch, 2010b; Hughes, 1987; Latour, 2011; Pinch \& Bijker, 1984;).

Geradora de falsas percepções, essa falsa distinção redutora tenta impor um princípio de divisão arbitrário e juízo de valor específico de um determinado grupo de agentes como algo legítimo. Assim, ela se fecha para importantes contribuições fornecidas pela desvalorizada "vertente europeia" que marcadamente rompem com as características que lhes são atribuídas e que foram acima expostas. Tal distinção se configura em um falso problema, uma vez que, conforme sinalizada na citação anterior ao afirmar que o "posicionamento americano, pelos problemas sociais com que nos deparamos, é mais produtivo, pois tem um caráter mais prático", propõe e impõe perguntas equivocadas para o encaminhamento de propostas pedagógicas ao contexto brasileiro.

A emergência e a colocação desses falsos problemas presentes nessas formas de classificação arbitrária do movimento CTS entre vertente norte-americana e vertente europeia consegue, ainda, operar alguns apagamentos que se mostram evidentes na história dominante, como por exemplo a ausência de referências históricas ao chamado Pensamento Latino Americano em Ciência-Tecnologia-Sociedade (PLACTS) (Dagnino \& Thomas, 2002; Vaccarezza, 2004). Dos trabalhos analisados, somente um faz referência direta ao PLACTS (Auler, 2002), mas ainda estabelece uma diferenciação histórica entre a história dominante e a particularidade da América Latina.

No lugar de se questionar que elementos são interessantes e necessários para se desenvolver propostas curriculares no Brasil, independente de sua origem geográfica e da imagem estigmatizada que dela se faz, opta-se por questionar qual tradição é mais adequada, senão superior, apenas por referências a características arbitrárias tais como "acadêmico" e "prático", produzindo percepções que passam a ser transmitidas e reproduzidas de forma acrítica pelos demais agentes do subcampo. Logo, falsos problemas são importantes na medida em que definem - quando não polemizam, a baixíssimos custos teóricos, sem grande esforço intelectual de objetivação e análise (o que não quer dizer que não haja esforço simbólico considerável de convencimento coletivo) - o universo do que é considerado relevante e merecedor de reconhecimento, neste caso, o universo dos problemas e metodologias dominantes.

\section{Considerações finais}

As análises aqui apresentadas buscaram desvelar alguns instrumentos que caracterizam a manifestação do poder simbólico presente nas relações de dominação no interior do Subcampo Brasileiro de Pesquisa em Ensino de Ciências CTS que deixa-se 
transparecer nas (re)construções históricas dominantes contadas sobre o subcampo e para o subcampo em questão. O poder simbólico, um poder construído socialmente que somente se exerce se for reconhecido como legítimo - através da ignorância das escolhas arbitrárias presentes em sua gênese, que se fazem esquecer enquanto construção social é um poder capaz de "criar" a realidade, a partir da imposição (e aceitação) de uma visão de mundo particular, cujo efeito mais evidente é a propriedade de fazer ver e de fazer acreditar, de estabelecer crenças tidas como universais e verdadeiras e, assim, tornar-se "real" e "evidente".

Além de desvelar alguns mecanismos de dominação presentes no campo, o presente artigo teve o objetivo, ainda, de promover uma ruptura com a noção ingênua de senso comum sobre a história - caracterizada aqui por "historicismo espontâneo" e que contribui para a disseminação acrítica de diversos elementos e instrumentos de dominação aqui abordados. A história dominante é, na verdade, uma versão histórica que se impôs como dominante no campo e que se faz esquecer enquanto história construída socialmente por meio das lutas travadas pela definição das verdades legítimas do campo. Problematizá-la torna-se importante, pois a relação entre a história do campo e um agente determina tanto a visão desse agente sobre a história quanto sobre o estado das relações do campo de produção simbólica, uma vez que "as tomadas de posição sobre o passado radicam frequentemente [...] em tomadas de posição latentes sobre o presente ou, mais exatamente, contra adversários intelectuais do presente" (Bourdieu, 2010a, p. 78).

Nesse sentido, buscou-se aqui evidenciar que as (re)construções históricas dominantes atuam como manifestações de violência simbólica, cujo efeito desempenha papel importante na criação e consolidação dos atos de fé simbólica que possibilitam a criação desse artefato social que é o Subcampo Brasileiro de Pesquisa em Ensino de Ciências CTS. A objetivação do trabalho de mobilização presente e atuante na história do campo, caracterizado num esforço de unificação e universalização de interesses que produz parte significativa das representações que os agentes possuem de si próprios, e que transmitem para os demais campos de produção simbólica, permitiu explicitar e questionar alguns fundamentos que, até então, permaneciam como inquestionáveis no subcampo CTS.

Retomando a pergunta inicialmente apresentada para guiar a construção das análises aqui feitas - "Quais elementos e princípios simbólicos de dominação podem ser evidenciados nas construções históricas apresentadas na literatura dominante do Subcampo Brasileiro de Pesquisa em Ensino de Ciências CTS?” -, o sistema de categorias e dados elaborados, analisados e discutidos indicam a atuação de elementos presentes na literatura dominante do subcampo que permanecem visíveis e outros que são mantidos sublimados e invisíveis, todos atuantes intensivamente nas relações estabelecidas na estrutura das lutas entre os agentes situados no subcampo.

As categorias discutidas - o efeito da sigla CTS; a afirmação da existência objetiva e simbólica do movimento CTS; o contrato social; a illusio e a doxa; os problemas e 
metodologias dominantes; os elementos de diferenciação na estrutura; e os falsos problemas - e as rupturas e avanços que elas proporcionaram evidenciam a necessidade de se pensar a história apresentada sobre o campo como uma versão da história do campo, a história dominante do campo, e que ela deve ser pensada relacionalmente, situando-a em meio às lutas estabelecidas, motivadas pela illusio, e travadas na disputa pela definição de suas crenças e de seus fundamentos.

A ação histórica no subcampo, que se faz presente nas tomadas de posição e na ação dos agentes, nas estratégias objetivas e inconscientes, nas apostas e nos riscos, mobiliza as duas formas de história presentes no campo - a história no estado objetivado e a história no estado incorporado, constitutiva do habitus - numa dialética de autoafirmação e atualização da história no e pelo subcampo. A história objetivada, aquela presente nos objetos e nos símbolos, apenas "sobrevive" ao tempo histórico se se mantiver permanentemente atualizada, atuada e atuante. Isto significa que essa história somente consegue permanecer ativada, se fazendo presente, se conseguir encontrar nos corpos esquemas de percepção (habitus) em conformidade com essa história, capazes de compreendê-la e dar-lhe sentido. É na relação com a história incorporada, história feita hábito, presente nas representações e nas percepções, nos gostos e afinidades, nas escolhas e nas posições, no senso prático do jogo, que a história de fato se renova e se atualiza - e se transforma (Bourdieu, 2010a).

Questionar a história dominante, como aqui se buscou, é tentar também atualizar a história do subcampo, tanto objetivada quanto incorporada, com a lucidez teórica e prática de seus efeitos e suas limitações. Conscientes de que a tentativa de renovação histórica nada mais é que uma estratégia estabelecida no campo e contra o campo, interessada, ao mesmo tempo em que tenta se tornar interessante aos olhos dos demais agentes (concorrentes), o presente trabalho de objetivação buscou problematizar aspectos dessa história dominante que são considerados importantes. Ao pôr em questão os fundamentos do próprio campo por meio dessa problematização, que será permanentemente avaliada com a mesma atitude interessada (no jogo) daqueles que a objetivaram e aqui a escreveram, destaca-se por fim que a própria dinâmica do campo exige esses questionamentos e discussões, uma vez que "a própria definição dos critérios de julgamento e dos princípios de hierarquização estão em jogo na luta, ninguém é bom juiz porque não há juiz que não seja, ao mesmo tempo, juiz e parte interessada" (Bourdieu, 1983, p. 130).

\section{Referências}

Abreu, T. B., Fernandes, J. P. \& Martins, I. (2009). Uma Análise Qualitativa e Quantitativa da Produção Científica Sobre CTS (Ciência, Tecnologia e Sociedade) em Periódicos da Área de Ensino de Ciências no Brasil. Atas do VII Encontro Nacional de Pesquisa em Educação em Ciências, Florianópolis, SC. 
Aikenhead, G. (2005). Educación Ciencia-Tecnología-Sociedad (CTS): una buena idea como quiera que se le llame. Educación Química, 16(2), 114-124.

Alves-Filho J. P., \& Pinheiro, T. F. (2012). Instrumentação para o ensino de Física. Goiânia: FUNAPE/CIAR.

Amorim, A. C. R. (1995). O ensino de biologia e as relações entre ciência/tecnologia/ sociedade: o que dizem os professores e o currículo do ensino medio? (Dissertação de Mestrado em Educação). Faculdade de Educação, UNICAMP, Campinas.

Amorim, A. C. R. (1997). O ensino de biologia e as relações entre ciência/tecnologia/ sociedade: o que dizem os professores e o currículo do ensino médio? Anais do VI Encontro Perspectivas do Ensino de Biologia, São Paulo, SP.

Araújo, R. F. (2009). Os Grupos de Pesquisa em Ciência, Tecnologia e Sociedade no Brasil. Revista Brasileira de Ciência, Tecnologia e Sociedade, 1(1), 81-97.

Auler, D. (2002). Interações entre ciência-tecnologia-sociedade no contexto da formação de professores de ciências. (Tese de Doutorado em Educação Científica e Tecnológica). Universidade Federal de Santa Catarina, Florianópolis.

Auler, D., \& Bazzo, W. A. (2001). Reflexões para a implementação do movimento CTS no contexto educacional brasileiro. Ciência \& Educação, 7(1), 1-13.

Auler, D., \& Delizoicov, D. (2005). Alfabetização científico-tecnológica para quê? Ensaio: pesquisa em educação em ciências, 3(1), 105-115.

Auler, D., \& Delizoicov, D. (2006). Ciência-Tecnologia-Sociedade: relações estabelecidas por professores de ciências. Revista electrónica de enseñanza de las ciencias, 5(2), 337355.

Bardin, L. (2011). Análise de Conteúdo. São Paulo: Edições 70.

Bazzo, W. A. (1998). Ciência, Tecnologia e Sociedade e o contexto da educação tecnológica. Florianópolis: Editora UFSC.

Bazzo, W. A., Von-Linsingen, I., \& Pereira, L.T. V. (2003). Introdução aos estudos CTS (ciência, tecnologia e sociedade). Madrid: Organização dos Estados Ibero-americanos para a Educação, a Ciência e a Cultura.

Bloor, D. (2009). Conhecimento e imaginário social. São Paulo: UNESP.

Bogdan, R., \& Biklen, S. (1994). Investigação qualitativa em educação. Porto: Porto.

Bourdieu, P. (1983). O Campo Científico. In R. Ortiz (Org.). Pierre Bourdieu: sociologia (pp. 122-155). São Paulo: Ática.

Bourdieu, P. (2004a). Os usos sociais da ciência: Por uma sociologia clínica do campo científico. São Paulo: UNESP.

Bourdieu, P. (2004b). Para uma Sociologia da Ciência. Lisboa: Edições 70. 
Bourdieu, P. (2004c). Coisas Ditas. São Paulo: Brasiliense.

Bourdieu, P. (2008). A Produção da Crença: contribuição para uma economia dos bens simbólicos. Porto Alegre: Zouk.

Bourdieu, P. (2010a). O Poder Simbólico. Rio de Janeiro: Bertrand.

Bourdieu, P. (2010b). Razões Práticas: Sobre a teoria da ação. Campinas: Papirus.

Bourdieu, P. (2011). Homo Academicus. Florianópolis: UFSC.

Bourdieu, P. (2014). Sobre o Estado: cursos no Collège de France. São Paulo: Companhia das Letras.

Bourdieu, P., \& Chartier, R. (2012). O sociólogo e o historiador. Belo Horizonte: Autêntica. Callon, M. (1987). Society in the Making: The Study of Technology as a Tool for Sociological Analysis. In W. E. Bijker, T. P. Hughes, \& T. J. Pinch (Org.). The Social construction of technological systems: New directions in the sociology and history of technology (pp. 83-105). Cambridge: MIT press.

Cerezo, J. A. L. (2004). Ciência, Tecnologia e Sociedade: o estado da arte na Europa e nos Estados Unidos. In L. W. Santos, E. Y. Ichikawa, P. V. Sendin, \& D. F. Cargano (Org.). Ciência, Tecnologia e Sociedade: o desafio da interação (pp. 11-44). Londrina: IAPAR.

Chrispino, A., Lima, L. S., Albuquerque, M. B., Freitas, A. C. C., \& Silva, M. A. F. B. (2013). A Área CTS no Brasil Vista Como Rede Social: Onde Aprendemos? Ciência \& Educação, 19(2), 455-479.

Collins, H., \& Pinch, T. (2010a). O Golem à Solta: o que você deveria saber sobre tecnologia. Belo Horizonte: Fabrefactum.

Collins, H., \& Pinch, T. (2010b). Dr. Golem. Belo Horizonte: Fabrefactum.

Correa, A. L. L., \& Araùjo, M. S. T. (2011). Mapeamento e Análise de Artigos Científicos Publicados entre 2000-2010 sobre CTS no Ensino de Ciências: Pressupostos e Orientações Curriculares. Atas do VII Encontro Nacional de Pesquisa em Educação em Ciências. Campinas, SP.

Cruz, S. M. S. C. S., \& Zylbersztajn, A. (2001). O enfoque ciência, tecnologia e sociedade e a aprendizagem centrada em eventos. In M. Pietrocola (Org.). Ensino de Física: conteúdo, metodologia e epistemologia em uma concepção integradora (pp. 171-196). Florianópolis: UFSC.

Dagnino, R., \& Thomas, H. (2002). Panorama dos Estudos sobre Ciência, Tecnologia e Sociedade na América Latina. Taubaté: Cabral Editora/Livraria Universitária.

Dixon, B. (1976). Para que serve a ciência? São Paulo: Nacional/Ed. Da Universidade de São Paulo. 
Hughes, T. P. (1987). The Evolution of Large Technological Systems. In W. E. Bijker, T. P. Hughes, \& T. J. Pinch (Org.). The Social construction of technological systems: New directions in the sociology and history of technology (pp. 51-81). Cambridge: MIT press.

Kuhn, T. S. (2011). A estrutura das revoluções científicas. São Paulo: Perspectiva.

Latour, B. (2011). Ciência em Ação: como seguir cientistas e engenheiros sociedade afora. São Paulo: UNESP.

Lopes, N. C., Andrade, J. A. N., Queirós, W. P., Souza, R. R., \& Nardi, R. Carvalho, W. L. P. (2009). Tendências do Movimento CTS em dois Eventos Nacionais da Área de Ensino de Ciências. Atas do XVIII Simpósio Nacional de Ensino de Física. Vitória, ES.

Marcovich, A., \& Shinn, T. (2013). Robert K. Merton, fundador da sociologia da ciência: comentários, insights, críticas. In A. Marcovich, \& T. Shinn (Org.). Ensaios de sociologia da ciência (pp. 253-272). São Paulo: Associação Filosófica Scientiae Studia/Editora 34.

Merton, R. K. (1938). Science, Technology and Society in Seventeenth Century England. Osiris, 4(1), 360-632.

Merton, R. K. (2013a). A ciência e a ordem social (1938). In A. Marcovich, \& T. Shinn (Org.). Ensaios de sociologia da ciência (pp. 159-178). São Paulo: Associação Filosófica Scientiae Studia/Editora 34.

Merton, R. K. (2013a). A ciência e a estrutura social democrática (1942). In A. Marcovich, \& T. Shinn (Org.). Ensaios de sociologia da ciência (pp. 181-198). São Paulo: Associação Filosófica Scientiae Studia/Editora 34.

Mezalira, S. M. (2008). Enfoque CTS no Ensino de Ciências Naturais a partir de Publicações em Eventos Científicos no Brasil. (Dissertação de Mestrado em Educação nas Ciências). Universidade Regional do Noroeste do Estado do Rio Grande Do Sul, Ijuí.

Pedretti, E. G., Bencze, L., Hewitt, J., Romkey, L., \& Jivraj, A. (2006). Promoting issuesbased STSE perspectives in science teacher education: Problems of identity and ideology. Science \& Education, 17(8), 941-960.

Pinch, T. J., \& Bijker, W. E. (1984). The Social Construction of Facts and Artefacts: or How the Sociology of Science and the Sociology of Technology might Benefit Each Other. Social Studies of Science, 14(3), 399-441.

Ribeiro, T. V. (2015). O Subcampo Brasileiro de Pesquisa em Ensino de Ciências CTS (Ciência-Tecnologia-Sociedade): um espaço em construção. (Dissertação de Mestrado em Educação em Ciências e Matemática) Universidade Federal de Goiás, Goiânia.

Santos, W. L. P., \& Mortimer, E. F. (2002). Uma análise de pressupostos teóricos da abordagem CTS (Ciência-Tecnologia-Sociedade) no contexto da educação brasileira. Ensaio:Pesquisa em Educação em Ciências, 2(2), 1-23.

Shinn, T., \& Ragouet, P. (2008). Controvérsias sobre a ciência. São Paulo: Associação Filosófica Scientiae Studia/Editora 34. 
Sutil, N., Bortoletto, A., Carvalho, W., \& Carvalho, L. M. O. (2008). CTS e CTSA em Periódicos Nacionais em Ensino de Ciências/Física (2000-2007): Considerações Sobre a Prática Educacional em Física. Atas do XI Encontro de Pesquisa em Ensino de Física. Curitiba, RS.

Vaccarezza, L. S. (2004). Ciência, Tecnologia e Sociedade: o Estado da Arte na América Latina. In L. W. Santos, E. Y. Ichikawa, P. V. Sendin, \& D. F. Cargano (Org.) Ciência, Tecnologia e Sociedade: o desafio da interação (pp. 43-77). Londrina: Instituto Agronômico do Paraná.

Ziman, J. M. (1985). Enseñanza y aprendizaje sobre la ciencia y la sociedad. México: Fondo de Cultura Económica.

Thiago Vasconcelos Ribeiro

(b) http://orcid.org/0000-0003-0308-2374

Faculdade Unicamps

Goiânia, Brasil thiago.v.ribeiro@live.com

Aliny Tinoco Santos

http://orcid.org/0000-0003-1684-7524

Colégio Estadual João Barbosa Reis

Secretaria de Estado de Educação

Goiânia, Brasil alinytinoco@gmail.com

Luiz Gonzaga Roversi Genovese

http://orcid.org/0000-0002-7259-0519

Programa de Pós-Graduação em Educação em Ciências e Matemática Instituto de Física

Universidade Federal de Goiás

Goiânia, Brasil Igenovese@ufg.br

Submetido em 13 de Abril 2015

Aceito em 28 de Dezembro 2016

Publicado em $\mathbf{3 0}$ de Abril de 2017 